\title{
Uranium(VI) extraction from concentrated Egyptian wet-process phosphoric acid using a synergistic organophosphorous solvent mixture
}

\author{
Ahmed F. Abdel-Magied ${ }^{1}$ Mostafa I. Amin ${ }^{1}$
}

Received: 11 February 2015 / Accepted: 10 September 2015/Published online: 2 November 2015

(C) The Author(s) 2015. This article is published with open access at Springerlink.com

\begin{abstract}
Uranium(VI) recovery from concentrated Egyptian hemi-dihydrate wet-process phosphoric acid, 9.2 M, is investigated using synergistic organophosphorous solvent mixture of dinonyl phenyl phosphoric acid (DNPPA) and tris(2-ethylhexyl)phosphate (TEP). The effect of various factors such as [DNPPA] concentration, [TEP] concentration, phosphoric acid concentration, shaking time, aqueous: organic phase's ratio $\left(V_{\mathrm{aq}} / V_{\text {org }}\right)$, stability of the solvent, the diluents effect, and temperature on the degree of extraction has been established. The effect of different stripping agents was investigated. The enthalpy change of the uranium extraction process was determined and the extracted uranium is further subjected to a second cycle of extraction [0.3 M D2EHPA + 0.075 M TOPO], scrubbing impurities ( $5 \mathrm{M}$ sulfuric acid), and finally stripping with $1 \mathrm{M}\left(\mathrm{NH}_{4}\right)_{2} \mathrm{CO}_{3}$ solution. Precipitation of uranium in highly pure $\mathrm{UO}_{3}$ product using hydrogen peroxide and heat treatment at $375^{\circ} \mathrm{C}$ were carried out.
\end{abstract}

Keywords Extraction - Uranium - Phosphoric acid . Organophosphorous solvent mixture

$\begin{array}{ll}\text { Abbreviations } \\ \text { DNPPA } & \text { Di-nonyl phenyl phosphoric acid } \\ \mathrm{K} & \text { Equilibrium constant } \\ \text { DBBP } & \text { Di-butyl butyl phosphonate } \\ \Delta \mathrm{H}^{\mathrm{O}} & \text { Standard enthalpy }(\mathrm{kJ} / \mathrm{mol}) \\ \mathrm{D} 2 \mathrm{EHPA} & \text { Di-(2-ethylhexyl) phosphoric acid } \\ \mathrm{V} & \text { Volume }\end{array}$

Mostafa I. Amin

mostafa_nma@yahoo.com

1 Nuclear Materials Authority, P.O. Box 530, El Maadi, Cairo, Egypt

$\begin{array}{ll}\text { TOPO } & \text { Tri-octyl phosphine oxide } \\ x & \text { Slope } \\ \text { TBP } & \text { Tri-butyl phosphate } \\ \Delta \mathrm{H} & \text { Enthalpy }(\mathrm{KJ} / \mathrm{mol}) \\ \text { PC88A } & \text { Mono 2-ethyl ester } \\ C & \text { Uranium concentration } \\ \text { WPPA } & \text { Wet-process phosphoric acid } \\ D_{\mathrm{u}} & \text { Distribution coefficient } \\ \text { TEP } & \text { Tris-(2-ethylhexyl) phosphate } \\ \text { Aq } & \text { Aqueous phase } \\ \text { Org } & \text { Organic phase } \\ \text { EMF } & \text { Electromotive force } \\ T & \text { Absolute temperature }(\mathrm{K}) \\ E \% & \text { Uranium extraction efficiency } \\ R & \text { Universal gas constant }\left(8.314 \mathrm{~J} \mathrm{~K}^{-1} \mathrm{~mol}^{-1}\right) \\ V_{\mathrm{aq}} / V_{\text {org }} & \text { Volume ratio between aqueous phase and } \\ & \text { organic phase }\end{array}$

\section{Introduction}

Uranium plays an important role in the generation of nuclear power but has limited resources. Efforts are being made worldwide to investigate the newer resources of uranium to meet the required demands. Among the secondary resources of uranium, natural phosphates are found to contain several tens to hundreds parts per million of uranium depending upon the origin of phosphate rocks [1]. Phosphoric acid becomes a potential source of uranium since during the acid digestion of phosphate rocks; most of the uranium (>90\%) reports in phosphoric acid [2] hence the acid product may contain up to $300 \mathrm{ppm}$ uranium together with other rare metals such as $\mathrm{V}, \mathrm{Cd}$, and $\mathrm{Co}$ and radionuclides like $\mathrm{Th}$ and 
Ra [3]. Uranium separation from fertilizer products also serves the objective of controlling its release into the human environment, including the food chain [4].

In general, solvent extraction has been found to be a successful process for industrial recovery of uranium from phosphate [2, 5-11], although other different methods such as ion-exchange [12], membrane separation [13], and precipitation [14] have been also extensively investigated. Various types of organophosphorous compounds and amides are used to carry out the separation of uranium [15]. Synergistic extraction is an important technique to increase the solvent extraction efficiency, and usually occurs when a cationic exchanger is mixed with a solvating agent. Using mixtures of extractants may increase the extractability and selectivity of metals, however, the opposite effect may occur with certain mixtures (antagonism effect), where the interaction between extractant molecules in the mixture are so strong that the metal distribution coefficient dramatically decreases compared to single system. Generally, the two extractants are interacting with one another to some extent in the organic phase, and the formation of mixedextractant metal product species must be strong enough for net synergism to be observed. A more comprehensive account is provided elsewhere [2].

In previous studies, we have shown that synergistic mixtures of D2EHPA-TOPO [16], PC88A-DBBP [17], and D2EHPA-DBBP [18] are suitable for successful extraction of hexavalent uranium from wet phosphoric acid (WPA). Di-nonyl phenyl phosphoric acid (DNPPA) has been shown to be a powerful extractant $[19,20]$. In the present paper, the synergistic combination of DNPPA with TEB for the extraction of uranium from concentrated WPA is described.

\section{Experimental procedures}

\section{Solutions, reagents, and analytical procedure}

Lambada3 UV-Vis spectrophotometer (Perkin-Elmer, USA) and atomic absorption spectrometer, GBC 932-AA supplied with acetylene and nitrous oxide burner heads, regulators, and integrated readings for absorbance, concentration, or emission intensity were used for determination of uranium and other metal ions. Uranium was analyzed by the ArsenazoIII method [21]. Absorbance of the formed uranium ArsenazoIII complex was measured at $650 \mathrm{~nm}$ against proper standard solutions.

Experimental tests were carried out using a wet-process phosphoric acid sample provided by Abu-Zaabal Co, Egypt that contained $44 \% \quad \mathrm{P}_{2} \mathrm{O}_{5}$ and $62 \mathrm{ppm}$ uranium. The chemical composition of the test sample is shown in Table 1. The pre-treatment was carried out by filtering the
Table 1 Chemical composition of Egyptian phosphoric acid

\begin{tabular}{llll}
\hline Constituent & $\mathrm{g} / \mathrm{L}$ & Constituent & $\mathrm{g} / \mathrm{L}$ \\
\hline $\mathrm{P}_{2} \mathrm{O}_{5}$ & 440 & $\mathrm{Mn}$ & 6.73 \\
$\mathrm{SO}_{4}{ }^{2-}$ & 61 & $\mathrm{Zn}$ & 3.58 \\
$\mathrm{Fe}$ & 25 & $\mathrm{U}$ & 0.062 \\
$\mathrm{Ca}$ & 2.6 & $\mathrm{~Pb}$ & 0.054 \\
$\mathrm{Mg}$ & 1.7 & $\mathrm{Ni}$ & 0.008 \\
\hline
\end{tabular}

phosphoric acid for removal of suspended solid particles (using Whatman filter paper, diam. $512 \mathrm{~mm}$ ), treated with activated carbon for removal of soluble organic matter, which is a very important factor for the success of uranium recovery, and finally oxidized with hydrogen peroxide till electromotive force (EMF) is $>450 \mathrm{mV}$. It was found that long-chain polymeric flocculant be used for the separation of suspended solids from freshly produced acid was also effective in partial removal of organic matter.

Di-nonyl phenyl phosphoric acid (DNPPA) was synthesized in our laboratory containing $88-91 \%$ diester, 4-5\% monoester, and 6-8\% neutral, which was further purified to $>94 \%$ diester and $<0.8 \%$ monoester by the known procedure [22]. Tris(2-ethylhexyl) phosphate (TEP) $98 \%$ used was obtained from indigenous sources while the diluents used was kerosene from MISR-Petroleum Ltd. Company, Egypt, and had main properties as specific gravity 0.8 ; flash point $70{ }^{\circ} \mathrm{C}$; initial boiling point $200{ }^{\circ} \mathrm{C}$; final boiling point $250{ }^{\circ} \mathrm{C}$; aromatics $<1 \%$. The extraction experiments were performed in $100 \mathrm{~mL}$ separating funnels, it is very important to note that no third phase or any precipitation was observed during the extraction process and uranium were analyzed in the aqueous phase and the content in the organic phase was calculated by mass balance. From latter values, the uranium extraction efficiency $E \%$ and distribution coefficients $D_{\mathrm{u}}$ were properly determined as

$E \%=\frac{100 D_{\mathrm{u}}}{D_{\mathrm{u}}+V_{\mathrm{aq}} / V_{\text {org }}}$

$D_{\mathrm{u}} \%=\frac{C_{(\text {orgphase })}}{C_{(\text {aqphase })}}$

where $C_{\text {(org phase) }}$ and $C_{(\text {aq phase) }}$ are the uranium concentrations in the organic and aqueous phase, respectively.

\section{Results and discussion}

\section{Variation of DNPPA concentration on uranium(VI) extraction}

The effect of Di-nonyl phenyl phosphoric acid (DNPPA) concentration on uranium(VI) extraction distribution 


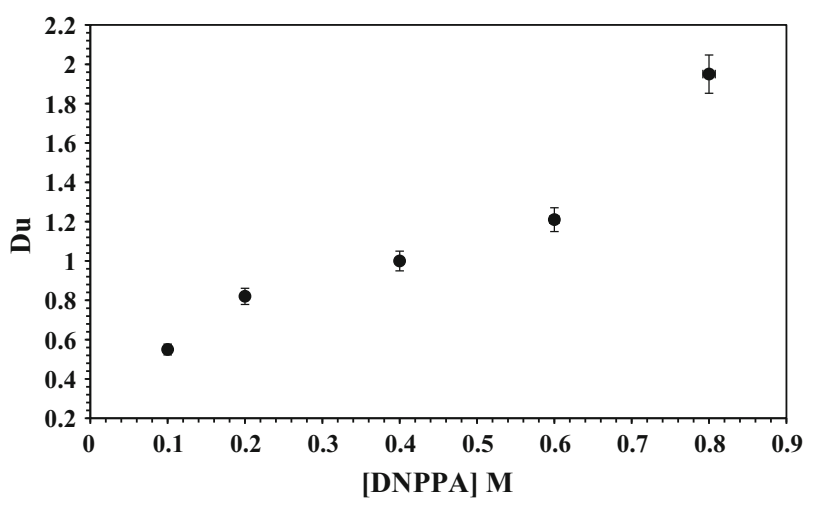

Fig. 1 Effect of DNPPA concentration on the distribution coefficient; $\mathrm{H}_{3} \mathrm{PO}_{4}=9.2 \mathrm{M}$, shaking time $=5 \mathrm{~min}, V_{\mathrm{aq}} / V_{\text {org }}=1 / 1$, at room temperature

coefficient from WPPA was studied; a series of extraction experiments was performed using di-nonyl phenyl phosphoric acid (DNPPA)/Kerosene in various concentrations [0.1-0.8] M. In these experiments, the other extraction conditions were fixed at a $V_{\mathrm{aq}} / V_{\text {org }}$ ratio of $1 / 1$ and using $5.0 \mathrm{~min}$ shaking time at room temperature. From the obtained results shown in Fig. 1, it is shown that the uranium extraction efficiency increases with increasing initial di-nonyl phenyl phosphoric acid (DNPPA) concentration.

\section{Variation of TEP concentration on uranium(VI) extraction at constant DNPPA}

The addition of tris (2-ethylhexyl) phosphate (TEP) to the organic phase lead to an enhancement in the uranium(VI) extraction distribution coefficient. The synergistic effect of tris (2-ethylhexyl) phosphate (TEP) concentration on the extraction percent of uranium is investigated. A set of experiments were performed by shaking the treated phosphoric acid with TEP having concentration ranging from [0.1 to 0.5] $\mathrm{M}$ at constant di-nonyl phenyl phosphoric acid (DNPPA) concentration $0.6 \mathrm{M}$ and in $V_{\text {aq }} / V_{\text {org }}$ ratio equal $1 / 1$ for $5.0 \mathrm{~min}$ at room temperature. The obtained results shown in Fig. 2 indicate that the distribution coefficient increases with increased tris (2-ethylhexyl) phosphate (TEP) concentration up to $0.3 \mathrm{M}$ followed by slight increase at higher TEP concentration. From these results, it is shown that tris (2-ethylhexyl) phosphate (TEP) has a good synergistic effect on the extraction of uranium from commercial wet-process phosphoric acid. A plot of $\log \mathrm{D}$ vs. $\log$ [TEP] at constant Di-nonyl phenyl phosphoric acid (DNPPA) concentration of $0.6 \mathrm{M}$ is presented graphically in Fig. 3 showing a slope of $\approx 1$, which indicates that $1 \mathrm{~mol}$ of uranium in the organic phase, is associated with $1 \mathrm{~mol}$ of TEP.

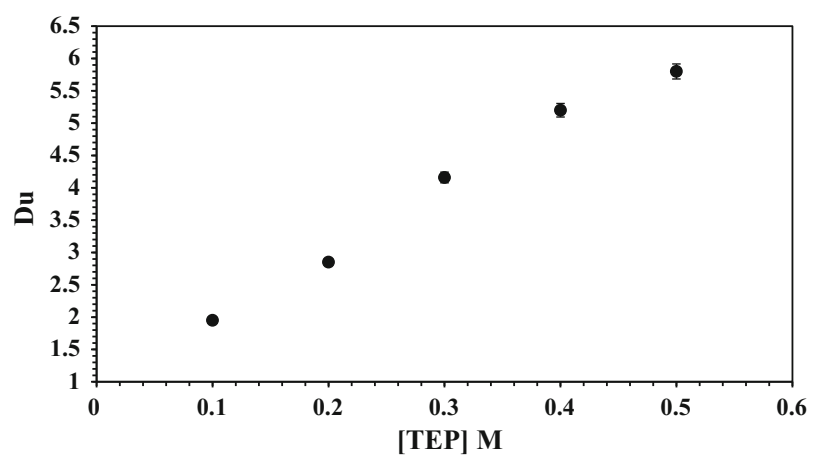

Fig. 2 Effect of TEP: DNPPA mole ratio on the distribution coefficient; $\mathrm{H}_{3} \mathrm{PO}_{4}=9.2 \mathrm{M}$, shaking time $=5 \mathrm{~min}, V_{\mathrm{aq}} / V_{\text {org }}=1 / 1$, $\mathrm{DNPPA}=0.6 \mathrm{M}$, at room temperature

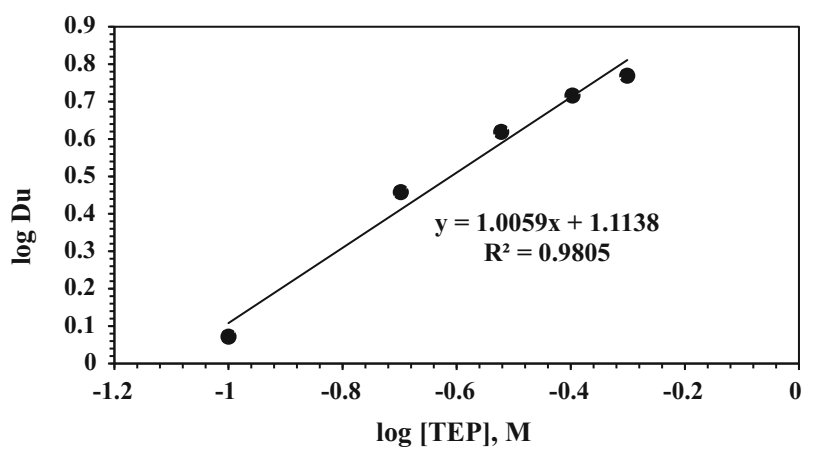

Fig. 3 Relation between $\log$ uranium distribution coefficient $\left(\log D_{\mathrm{u}}\right)$ vs. $\log [\mathrm{TEP}] \mathrm{M}$, at constant [DNPPA] concentration, $\mathrm{H}_{3} \mathrm{PO}_{4}=9.2 \mathrm{M}, \quad$ shaking $\quad$ time $=5 \mathrm{~min}, \quad V_{\mathrm{aq}} / V_{\text {org }}=1 / 1$, $\mathrm{DNPPA}=0.6 \mathrm{M}$, at room temperature

\section{Variation of DNPPA concentration on uranium(VI) extraction at constant TEP concentration [0.3] M}

The behavior of di-nonyl phenyl phosphoric acid (DNPPA) concentration on the extraction of uranium(VI) from WPPA in the presence of $0.3 \mathrm{M}$ TEP is studied by shaking phosphoric acid with di-nonyl phenyl phosphoric acid (DNPPA) at a concentration ranging from [0.1 to 0.8] $\mathrm{M}$ at room temperature for a shaking time of $5.0 \mathrm{~min}$ and in $V_{\mathrm{aq}} /$ $V_{\text {org }}$ ratio equal to $1 / 1$. The results are graphically represented in Fig. 4 as a relation between the uranium extraction distribution coefficient and di-nonyl phenyl phosphoric acid (DNPPA) concentration. The experimental results indicate that the extraction distribution coefficient increases with increase in Di-nonyl phenyl phosphoric acid (DNPPA) concentration. From the results, $0.6 \mathrm{M}$ of DNPPA concentration is preferred due to economic reasons. The extractant system with more than $0.6 \mathrm{M}$ DNPPA + 0.3 M TEP is too viscous, more expensive, and difficult in industrial scale operation. The plot of $\log D_{\mathrm{u}}$ vs. $\log$ [DNPPA] $\mathrm{M}$ is shown in Fig. 5 and indicates a linear 


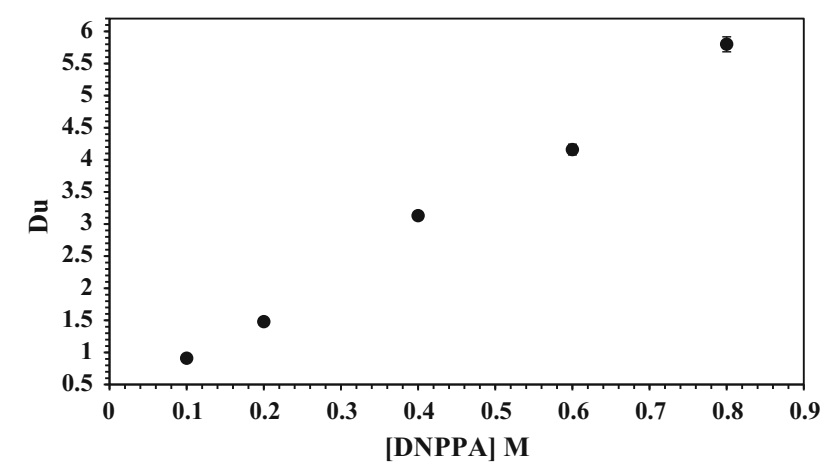

Fig. 4 Effect of DNPPA: TEP mole ratio on the distribution coefficient, $\mathrm{H}_{3} \mathrm{PO}_{4}=9.2 \mathrm{M}$, shaking time $=5 \mathrm{~min}, V_{\mathrm{aq}} / V_{\text {org }}=1 / 1$, $\mathrm{TEP}=0.3 \mathrm{M}$, at room temperature

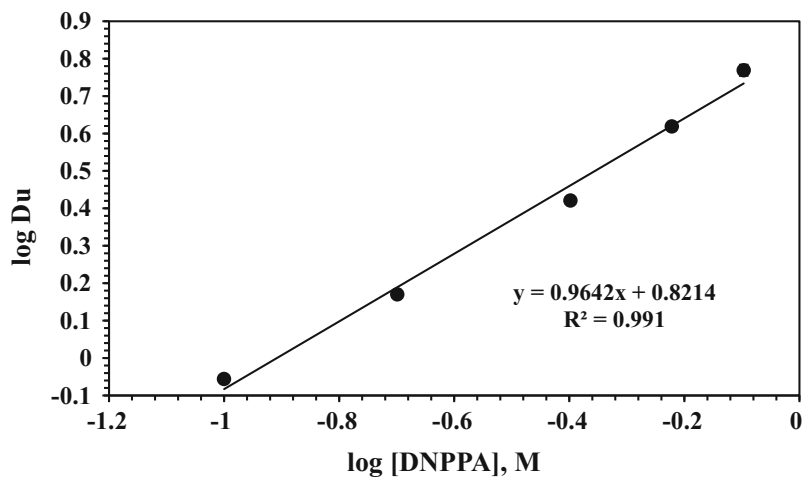

Fig. 5 The plot of $\log$ uranium distribution coefficient $\left(\log D_{\mathrm{u}}\right)$ vs. $\log [$ DNPPA $] \mathrm{M}$, at constant TEP, $\mathrm{H}_{3} \mathrm{PO}_{4}=9.2 \mathrm{M}$, shaking time $=5 \mathrm{~min}, V_{\mathrm{aq}} / V_{\text {org }}=1 / 1, \mathrm{TEP}=0.3 \mathrm{M}$, at room temperature

relationship with slope $\sim 1$. This contrasts with the results on DNPPA-TBP system where second-order dependence is observed [19].

\section{Variation of phosphoric acid concentration}

Phosphoric acid concentration effect on the extraction of uranium(VI) by 0.6 M DNPPA + 0.3 MTEP was investigated. The concentration of the feed acid was in the range of [4.06 to 9.23] $\mathrm{M}$ with the following conditions: shaking time of $5.0 \mathrm{~min}, V_{\mathrm{aq}} / V_{\text {org }}$ ratio equal to $1 / 1$, and at room temperature. From the obtained data plotted in Fig. 6, it can be shown that uranium extraction efficiency decreases by increasing the concentration of phosphoric acid. By using the $\log -\log$ plot of $D_{\mathrm{u}}$ and phosphoric acid concentration as shown in Fig. 7, the linear relationship with slope $\approx-2$, indicates that $2 \mathrm{~mol}$ of proton are librated for extraction of $1 \mathrm{~mol}$ of uranium, and the plausible extraction equilibrium is postulated as

$\mathrm{UO}_{2}^{2+}+(\mathrm{HX})_{2}+\mathrm{TEP} \rightarrow \mathrm{UO}_{2} \mathrm{X}_{2} \cdot \mathrm{TEP}+2 \mathrm{H}^{+}$,

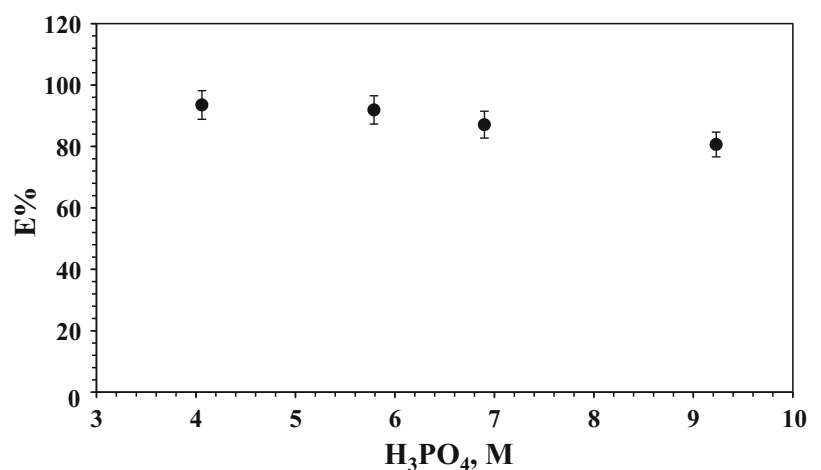

Fig. 6 Variation of uranium extraction efficiency $(E \%)$ against $\mathrm{H}_{3} \mathrm{PO}_{4} \quad$ concentration, $\quad V_{\text {aq }} / V_{\text {org }}=1 / 1, \quad$ DNPPA $=0.6 \mathrm{M}$, $\mathrm{TEP}=0.3 \mathrm{M}$, time $=5 \mathrm{~min}$, at room temperature

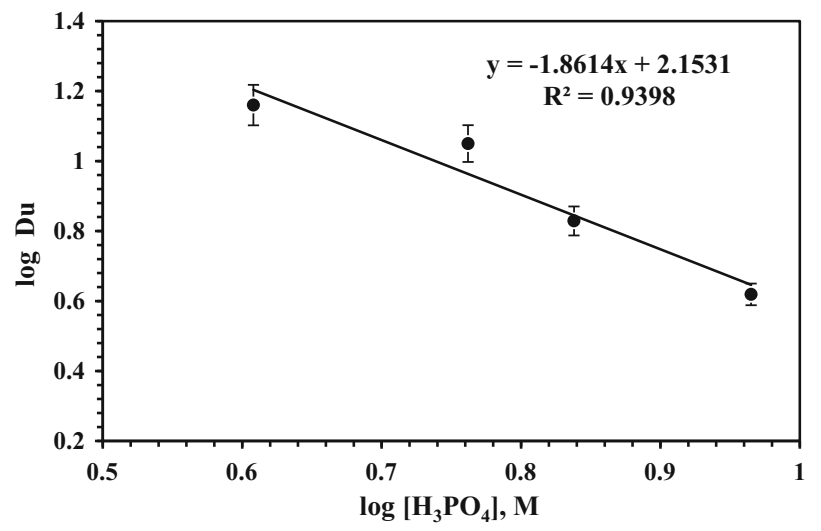

Fig. 7 The plot of $\log$ uranium distribution coefficient $(\log D)$ vs. $\log$ $\left[\mathrm{H}_{3} \mathrm{PO}_{4}\right] \mathrm{M}$, at constant [0.6 M DNPPA + 0.3 M DBBP] concentration. $V_{\mathrm{aq}} / V_{\mathrm{org}}=1 / 1$, shaking time $=5 \mathrm{~min}$, at room temperature

where $(\mathrm{HX})_{2}$ is a dimmer of DNPPA. This is similar to the extraction of hexavalent uranium in DEHPA-TOPO system $[23,24]$ and DOPPA-TOPO system [25].

\section{Effect of aqueous/organic phase ratio}

The effect of the $V_{\mathrm{aq}} / V_{\text {org }}$ ratio on uranium(VI) extraction from concentrated Egyptian phosphoric acid, 9.2 M, was investigated at $V_{\mathrm{aq}} / V_{\text {org }}$ ratio varying from $1 / 1$ to $4 / 1$. All experiments were performed using $0.6 \mathrm{M}$ DNPPA + 0.3 M TEP diluted in kerosene for a mixing time of $5.0 \mathrm{~min}$ at room temperature. At 1:1 phase ratio, uranium extraction increases parallel to the organic concentration and eventually $81 \%$ extraction is achieved (c.f. Table 2). As the aqueous to organic phase ratio increases, uranium extraction efficiency drops to a minimum of $40 \%$ (see Table $2, V_{\mathrm{aq}} / V_{\mathrm{org}}=4: 1$ ). From the obtained results, an aqueous/organic phase ratio of 1:2 was chosen for economic reasons. 
Table 2 Effect of aqueous/organic phase ratio on uranium distribution ratio from Egyptian concentrated phosphoric acid, $9.2 \mathrm{M}$, by $0.6 \mathrm{M}$ DNPPA + 0.3 M TEP in kerosene

\begin{tabular}{llcl}
\hline$V_{\text {aq }} / V_{\text {org }}$ phase ratio & \multicolumn{2}{l}{$U$ concentration, ppm } & $D_{\mathrm{u}}$ ratio \\
\cline { 2 - 3 } & $\mathrm{aq}$ & org & \\
\hline $1 / 1$ & 12 & 50 & 4.17 \\
$2 / 1$ & 17 & 45 & 2.64 \\
$3 / 1$ & 29 & 33 & 1.13 \\
$4 / 1$ & 37 & 25 & 0.68 \\
\hline
\end{tabular}

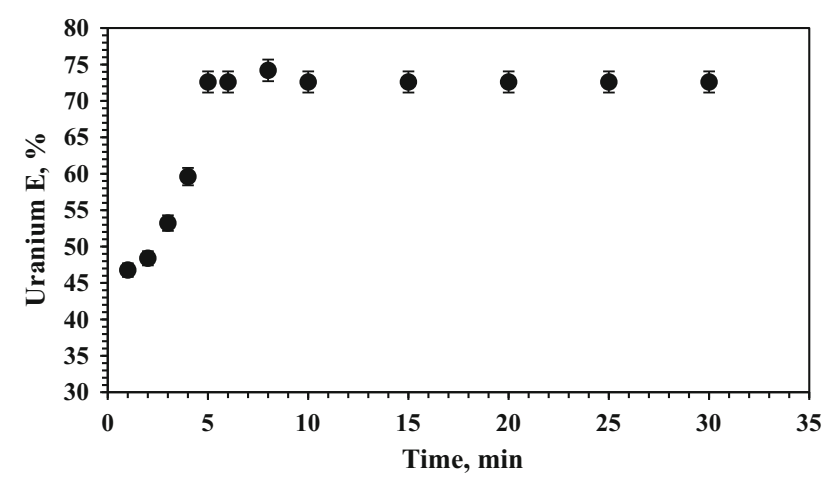

Fig. 8 Variation of uranium extraction efficiency $(E \%)$ against time, $\mathrm{H}_{3} \mathrm{PO}_{4}=9.2 \mathrm{M}, V_{\text {aq }} / V_{\text {org }}=2 / 1, \mathrm{DNPPA}=0.6 \mathrm{M}, \mathrm{TEP}=0.3 \mathrm{M}$, at room temperature

\section{Effect of shaking time on uranium(VI) extraction}

The effect of shaking time on the uranium(VI) extraction efficiency from concentrated Egyptian phosphoric acid, $9.2 \mathrm{M}$, by $0.6 \mathrm{M}$ DNPPA $+0.3 \mathrm{M}$ TEP/kerosene was studied by performing another series of extraction experiments using different shaking times ranging from 1 to $30 \mathrm{~min}$. In these experiments, the other extraction conditions were fixed at a $V_{\mathrm{aq}} / V_{\text {org }}=2 / 1, T=25{ }^{\circ} \mathrm{C}$ for various time intervals. Figure 8 shows the variation of uranium extraction efficiency $(E \%)$ against time. From the obtained data, it was found that the system reached equilibrium at $5.0 \mathrm{~min}$.

\section{Effect of diluents on uranium(VI) extraction}

The effect of different diluents in uranium(VI) extraction efficiency was investigated. 0.6 M DNPPA + 0.3 M TEP were mixed in different diluents for 5.0 min shaking time at room temperature. From the obtained data in Fig. 9, it is shown that, diluents affect the extraction of metal ions as

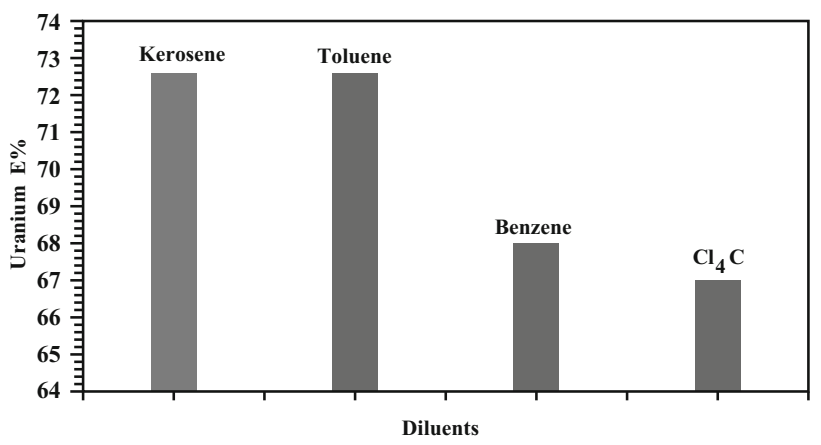

Fig. 9 Effect of diluents on the uranium extraction efficiency $(E \%)$ by using $0.6 \mathrm{M}$ DNPPA $+0.3 \mathrm{M}$ TEP, $\mathrm{H}_{3} \mathrm{PO}_{4}=9.2 \mathrm{M}, \quad V_{\mathrm{aq}} /$ $V_{\text {org }}=2 / 1$, at room temperature

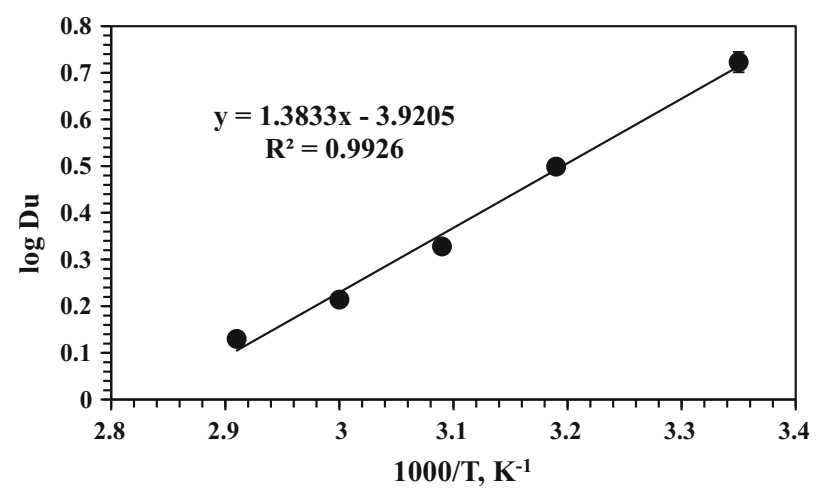

Fig. 10 Effect of temperature on the distribution coefficient of uranium; $V_{\mathrm{aq}} / V_{\text {org }}=2$, DNPPA $=0.6 \mathrm{M}$, TEP $=0.3 \mathrm{M}$, shaking time $=5 \mathrm{~min}$

they play an important role in solubilizing the water released from the co-ordination sphere (Fig. 10).

\section{Effect of temperature on uranium(VI) extraction}

Uranium(VI) extraction from phosphoric acid, 9.2 M, at different temperatures was investigated. The result shows that by increasing the temperature, the uranium distribution coefficient is decreased, which demonstrates the exothermic nature of the extraction process. Therefore, the applied temperature was room temperature $\left(25^{\circ} \mathrm{C}\right)$. The effect of temperature on the distribution coefficient can be quantified by making use of the Van't Hoff equation. The plot of $\log D_{\mathrm{u}}$ against $1 / T$ yields a straight line equation with slope $(x)=-\Delta \mathrm{H}^{\circ} / 2.303 \mathrm{R}$ (c.f. Fig. 10) which shows that the extraction of uranium by $6 \mathrm{M}$ DNPPA $+0.3 \mathrm{M}$ TEP/kerosene decreases with temperature. An enthalpy change of $-26.49 \mathrm{~kJ} / \mathrm{mol}$ was 


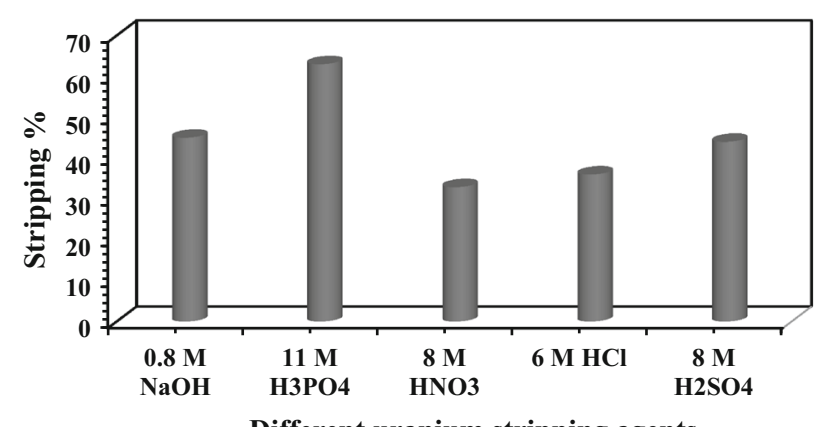

Different uranium stripping agents

Fig. 11 Different stripping agents for stripping of uranium from loaded organic solvent 0.6 M DNPPA + 0.3 M TEP

determined, which indicates that the extraction is an exothermic process. This is in agreement with the reported enthalpy change for hexavalent uranium extraction from wet-process phosphoric acid using the synergistic solvent mixture of DEHPA-TOPO system $(-35.8 \mathrm{~kJ} / \mathrm{mol})$ [26].

\section{Stability test of the extractant}

In two parallel experiments, aliquots of $0.6 \mathrm{M}$ DNPPA + 0.3 M TEP/kerosene were mixed with $9.2 \mathrm{M}$ Egyptian phosphoric acid at room temperature at $70{ }^{\circ} \mathrm{C}$, respectively for 15 days. Samples of the organic phase were withdrawn at intervals and uranium extraction test was carried out. No detectable change in uranium extraction efficiency $(E \%)$ was found during this period indicating good stability of the solvent toward strong acid and temperature.

\section{Stripping of uranium from extract}

The stripping process of uranium from the synergistic $0.6 \mathrm{M}$ DNPPA $+0.3 \mathrm{M}$ TEP mixtures at room temp using different stripping agents was investigated. Figure 11 shows the different striping agents used in this study. The preferred stripping results were found to be pure phosphoric acid concentration: $11 \mathrm{M}$ (containing $10 \mathrm{~g} / \mathrm{L} \mathrm{Fe}^{2+}$ ); temperature: $60-70{ }^{\circ} \mathrm{C}$; contact time: $4.0 \mathrm{~min}$; org/aq phase ratio equal 20/1; and five stages were sufficient for stripping about $98 \%$ of total uranium in loaded organic.

\section{Recovery of uranium from strip solution}

In order to recover uranium from the strip solution obtained in the first cycle, the strip solution undergoes a second cycle of extraction-stripping with an additional scrubbing step by $5 \mathrm{M}$ sulfuric acid incorporated to obtain
Table 3 Impurity analysis of uranium peroxide hydrate

\begin{tabular}{llll}
\hline Element & $\mathrm{ppm}$ & Element & $\mathrm{ppm}$ \\
\hline $\mathrm{Y}$ & 2.8 & $\mathrm{Eu}$ & 0.18 \\
$\mathrm{Gd}$ & 0.81 & $\mathrm{Sm}$ & 1.7 \\
$\mathrm{Ce}$ & 5.5 & $\mathrm{Fe}$ & 0.06 \\
$\mathrm{Dy}$ & 2.6 & $\mathrm{~B}$ & 2.4 \\
\hline
\end{tabular}

a uranium cake of high purity. The extractant used in the second cycle was $0.3 \mathrm{M}$ D2EHPA $+0.075 \mathrm{M}$ TOPO, as per earlier reports [27]. Uranium was stripped from the loaded organic phase with $1 \mathrm{M}$ ammonium carbonate solution. The strip liquor was filtered to remove traces of iron precipitate. Uranium precipitation was carried out using $\mathrm{H}_{2} \mathrm{O}_{2}$ due to its superior selectivity toward uranyl ion in acidic media [28]. In order to bring down the $\mathrm{pH}$ of the solution, an addition of sulfuric acid to the solution with a slight excess of $\mathrm{H}_{2} \mathrm{O}_{2}$ was added after the solution had been filtered to remove the traces of iron hydroxide precipitate, and the neutralization was carried out with sulfuric acid. In a $\mathrm{pH}$ range of 3-4, the uranium precipitation was complete $(99 \%)$. Uranium peroxide hydrate was filtered, washed with ammonium hydroxide $\left(\mathrm{NH}_{4}\right.$ $\mathrm{OH})$, dried and finally calcined at $375{ }^{\circ} \mathrm{C}$ to obtain $\mathrm{UO}_{3}$ powder with high purity. Table 3 shows the chemical analysis of the final product and Fig. 12 shows a general scheme for the overall uranium extraction process from the concentrated phosphoric acid. The overall uranium recovery yield was $\approx 95 \%$ indicating that the synergistic organophosphorous solvent mixture of DNPPA and TEP is suitable for the recovery of uranium form concentrated wet-process phosphoric acid $9.2 \mathrm{M}$, compared to the classical organophosphorous solvent mixture of D2HEPA and TOPO (i.e., the rate of uranium extraction from even pure $[5,6] \mathrm{M}$ phosphoric acid using D2HEPA + TOPO extractant is known to be relatively slow under the best conditions).

\section{Conclusion}

This paper reported the uranium(VI) extraction from Egyptian concentrated phosphoric acid using DNPPA and TEP as extractants. The extraction of uranium is found to be better when the concentrations of DNPPA and TEP are 0.6 and $0.3 \mathrm{M}$, respectively. An extraction mechanism for uranium has been postulated based on the results of slope analysis. The studies of the effect of diluents clearly indicate a role of diluent in extraction of uranium from aqueous solutions. High-purity uranium is recovered from the strip solution by a second cycle of extraction with $0.3 \mathrm{M}$ 
Fig. 12 Simplified flowsheet of the uranium extraction process

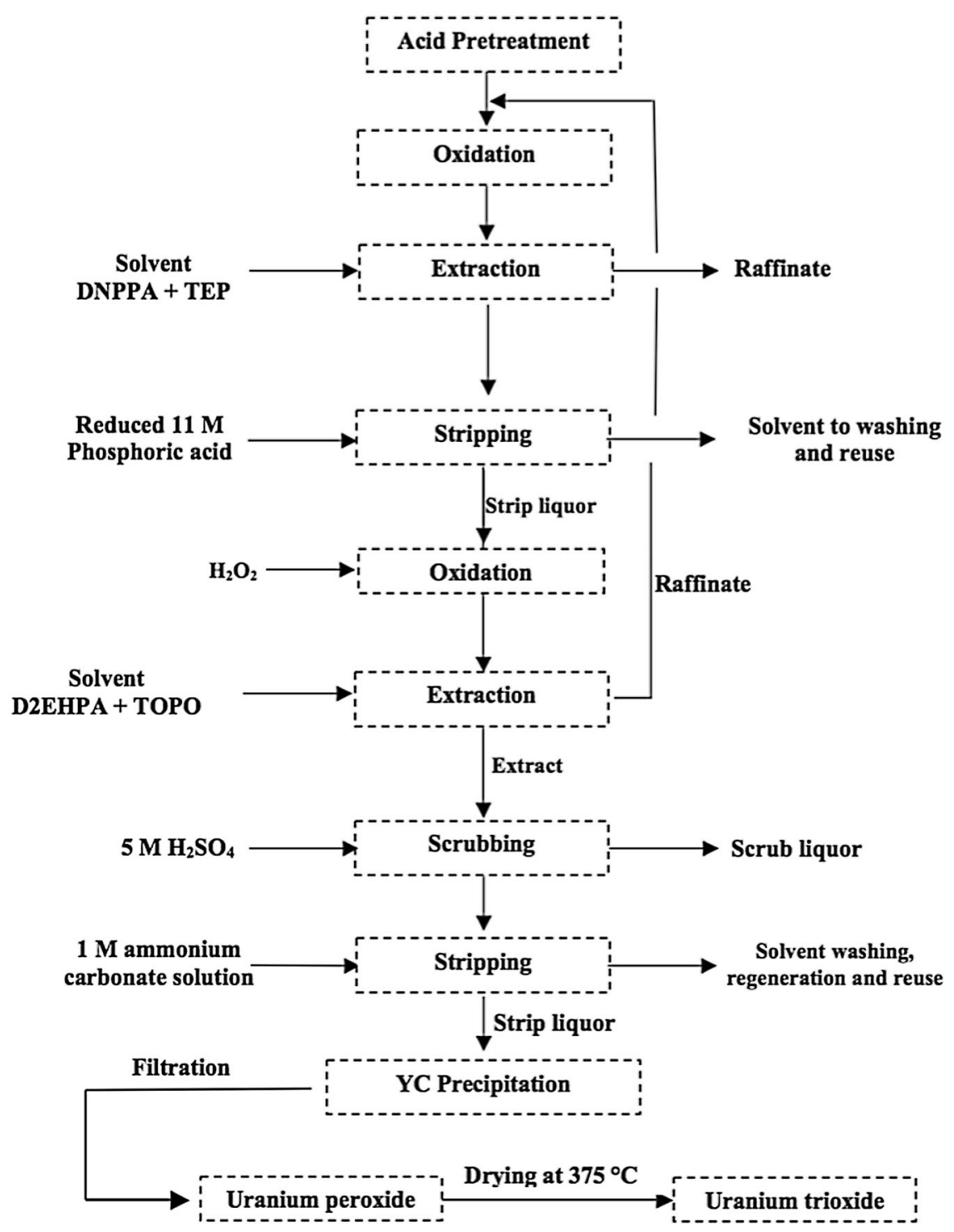

$\mathrm{D} 2 \mathrm{EHPA}+0.075 \mathrm{M}$ TOPO mixture. The stripping is performed by an alkaline solution, from the resulting alkaline uranium solution. The precipitation process yields high-purity uranium peroxide which is filtered, washed, dried, and calcined at $375{ }^{\circ} \mathrm{C}$.

Acknowledgments The authors wish to thank Dr. H.S. Gado, head of the phosphoric acid pilot plant, for his valuable help in carrying out the test work.

Open Access This article is distributed under the terms of the Creative Commons Attribution 4.0 International License (http://crea tivecommons.org/licenses/by/4.0/), which permits unrestricted use, distribution, and reproduction in any medium, provided you give appropriate credit to the original author(s) and the source, provide a link to the Creative Commons license, and indicate if changes were made.

\section{References}

1. Hurst FJ, Crouse DJ, Brown KB (1972) Recovery of uranium from wet-process phosphoric acid. Ind Eng Chem Process Des Dev 11:122-128

2. Beltrami D, Cote G, Mokhtari H, Courtaud B, Moyer BA, Chagnes A (2014) Recovery of uranium from wet phosphoric acid by solvent extraction processes. Chem Rev 114:12002-12023

3. Scholten LC, Timmermans CWM (1995) Natural radioactivity in phosphate fertilizers. Fertil Res 43:103-107

4. Sahu SK, Ajmal PY, Bhangare RC, Tiwari M, Pandit GG (2014) Natural radioactivity assessment of a phosphate fertilizer plant area. J Radiat Res Appl Sci 7:123-128

5. Beltrami D, Chagnes A, Mokhtari H, Courtaud B, Cote G (2014) Pysicochemical phenomena involved in the recovery of uranium from phosphate by BiDiBOPP/di-n-HMOPO and development of new cationic extractants. Procedia Eng 83:259-264 
6. Beltrami D, Chagnes A, Haddad M, Laureano H, Mokhtari H, Courtaud B, Jugé S, Cote G (2014) Solvent extraction studies of uranium(VI) from phosphoric acid: role of synergistic reagents in mixture with bis(2-ethylhexyl) phosphoric acid. Hydrometallurgy 144-145:207-214

7. Beltrami D, Mercier-Bion F, Cote G, Mokhtari H, Courtaud B, Simoni E, Chagnes A (2014) Investigation of the speciation of uranium(VI) in concentrated phosphoric acid and in synergistic extraction systems by time-resolved laser-induced fluorescence spectroscopy (TRLFS). J Mol Liq 190:42-49

8. Beltrami D, Chagnes A, Haddad M, Varnek A, Mokhtari H, Courtaud B, Cote G (2013) Recovery of uranium (VI) from concentrated phosphoric acid by mixtures of new bis(1,3dialkyloxypropan-2-yl) phosphoric acids and tri-n-octylphosphine oxide. Hydrometallurgy 140:28-33

9. Beltrami D, Cote G, Mokhtari H, Courtaud B, Chagnes A (2012) Modeling of the extraction of uranium (VI) from concentrated phosphoric acid by synergistic mixtures of bis-(2-ethylhexyl)phosphoric acid and tri- $n$-octylphosphine oxide. Hydrometallurgy 129-130:118-125

10. Beltrami D, Chagnes A, Haddad M, Laureano H, Mokhtari H, Courtaud B, Jugé S, Cote G (2012) Development of new cationic exchangers for the recovery of uranium (VI) from concentrated phosphoric acid. Sep Sci Technol 48:480-486

11. Yan-Zhao Y, Si-Xiu S, Sheng-Yu F (2002) Liquid-liquid extraction of uranium(VI) with 2-ethylhexyltolylsulfoxide (EHTSO). J Radioanal Nucl Chem 251:503-506

12. Kabay N, Demircioglu M, Yayli S, Gunay E, Yuksel M, Saglam M, Streat M (1998) Recovery of uranium from phosphoric acid solutions using chelating ion-exchange resins. Ind Eng Chem Res 37:1983-1990

13. Kulkarni PS, Mukhopadhyay S, Bellary MP, Ghosh SK (2002) Studies on membrane stability and recovery of uranium (VI) from aqueous solutions using a liquid emulsion membrane process. Hydrometallurgy 64:49-58

14. Weterings K, Janssen J (1985) Recovery of uranium, vanadium, yttrium and rare earths from phosphoric acid by a precipitation method. Hydrometallurgy 15:173-190

15. Biswas S, Hareendran KN, Singh DK, Sharma JN, Roy SB (2010) Extraction of $\mathrm{U}(\mathrm{VI})$ and $\mathrm{Th}(\mathrm{IV})$ from nitric acid medium using tri(butoxyethyl) phosphate (TBEP) in n-paraffin. J Radioanal Nucl Chem 283:665-668

16. Ali HF, Ali MM, Taha MH, Abdel-Magied AF (2012) Uranium extraction mechanism from analytical grade phosphoric acid using D2EHPA and synergistic D2EHPA-TOPO mixture. Int $\mathbf{J}$ Nucl Energy Sci Eng 2:57

17. Abdel-Khalek AA, Ali MM, Ashour RM, Abdel-Magied AF (2011) Chemical studies on uranium extraction from concentrated phosphoric acid by using PC88A and DBBP mixture. J Radioanal Nucl Chem 290:353-359

18. Abdel-Khalek A, Ali M, Hussein A, Abdel-Magied A (2011) Liquid-liquid extraction of uranium from Egyptian phosphoric acid using a synergistic D2EHPA-DBBP mixture. J Radioanal Nucl Chem 288:1-7

19. Singh H, Mishra SL, Vijayalakshmi R (2004) Uranium recovery from phosphoric acid by solvent extraction using a synergistic mixture of di-nonyl phenyl phosphoric acid and tri-n-butyl phosphate. Hydrometallurgy 73:63-70

20. Singh DK, Vijayalakshmi R, Singh H (2012) Studies on di-nonyl phenyl phosphoric acid (DNPPA): a potential extractant for uranium recovery from merchant grade phosphoric acid (MGA). Desalination Water Treatment 38:138-145

21. Marczenko Z (1986) Separation and spectrophotometric determination of elements, Horwood, Chichester

22. (1950) Organophosphorus compounds. By Gennady M. Kosolapoff. Wiley, New York. J Am Pharma Assoc 39: 704-704

23. Bunus FT, Domocoş VC, Dumitrescu P (1978) Synergic extraction of uranium from phosphate solutions with di-(2 ethylhexyl) phosphoric acid and tri- $n$-octylphosphine oxide. J Inorg Nucl Chem 40:117-121

24. Girgin S, Acarkan N, Sirkeci AA (2002) The uranium(VI) extraction mechanism of D2EHPA-TOPO from a wet process phosphoric acid. J Radioanal Nucl Chem 251:263-271

25. Krea M, Khalaf H (2000) Liquid-liquid extraction of uranium and lanthanides from phosphoric acid using a synergistic DOPPA-TOPO mixture. Hydrometallurgy 58:215-225

26. Khleifia N, Hannachi A, Abbes N (2013) Thermodynamic study of uranium extraction from tunisian wet process phosphoric acid. Int Sch Sci Res Innov 83:510-513

27. Singh H, Vijayalakshmi R, Mishra SL, Gupta CK (2001) Studies on uranium extraction from phosphoric acid using di-nonyl phenyl phosphoric acid-based synergistic mixtures. Hydrometallurgy 59:69-76

28. Kim K-W, Kim Y-H, Lee S-Y, Lee J-W, Joe K-S, Lee E-H, Kim J-S, Song K, Song K-C (2009) Precipitation characteristics of uranyl ions at different $\mathrm{pHs}$ depending on the presence of carbonate ions and hydrogen peroxide. Environ Sci Technol 43:2355-2361 